Odessa State Environmental University, L'vovskaya str.15, Odessa-16, 65016, Ukraine

e-mail: florkota@gmail.com

\title{
RELATIVISTIC CALCULATION OF OSCILLATOR STRENGTHS OF THE RADIATION TRANSITIONS BETWEEN BARIUM RYDBERG STATES
}

\begin{abstract}
The combined relativistic energy approach and relativistic many-body perturbation theory with the zeroth order DiracKohn-Sham one-particle approximation are used for preliminary estimating the energies and oscillator strengths of radiative transitions from the ground state to the low-excited and Rydberg states, in particular, 6s2 -6snp ( $\mathrm{n}=7-30)$ transitions, of the barium atom. The comparison of the calculated oscillator strengths with available theoretical and experimental (compillated) data is performed. The important point is linked with non-accounting for the polarization effect contribution into the oscillator strength value that has led to $\sim 40 \%$ difference between the empirical (compillated) and theoretical data.
\end{abstract}

\section{Introduction}

The research in many fields of modern atomic physics (spectroscopy, spectral lines theory, theory of atomic collisions etc), astrophysics, plasma physics, laser physics and quantum and photo-electronics requires an availability of sets of correct data on the energetic, spectroscopic and structural properties of atoms, especially in the high excited, Rydberg states. Naturally, the correct corresponding data about radiative decay widths, probabilities and oscillator strengths of atomic transitions are needed in building adequate astrophysical models, realizing regular astrophysical, laboratory, thermonuclear plasma diagnostics and in fusion research. Besides, a great interest to studying Rydberg atomic states parameters can be easily explained by a powerful development of such new fields as quantum computing, and quantum cryptography, construction of new type Rydberg atomic lasers etc. Traditionally, considerable attention is devoted to studying the energetic and spectral characteristics of the light atoms ( $\mathrm{H}, \mathrm{He}, \mathrm{Li}$ etc) and corresponding multicharged ions. However, studying spectral characteristics of heavy atoms and ions in the Rydberg states has to be more complicated as it requires a necessary accounting the relativistic, exchange-correlations effects and possibly the QED corrections for superheavy atomic systems. There have been sufficiently many reports of cal- culations and compilation of energies and oscillator strengths for the barium and even Ba-like ions (see, for example, [1-3] and refs. therein), however, an accuracy of theses data call for further serious analysis and calculation. In many papers the Dirac-Fock method, model potential approach, quantum defect approximation in the different realizations have been used for calculating the energy and spectral properties of barium and it has been shown that an account of the polarization interelectron corrections is of a great quantitative importance. The consistent relativistic perturbation theory calculations of the transitions energies and oscillator strengths for some chosen transitions between the Rydberg states are performed in Refs. [4]. However, it should be stated that for majority of the barium Rydberg states and Ba-like ions with high values of a nuclear charge $Z$, there is not enough precise information available in literatures [1-3]. In our paper the combined relativistic energy approach and relativistic many-body perturbation theory with the zeroth order Dirac-Kohn-Sham 1-particle approximation are used for preliminary estimating the energies and oscillator strengths of radiative transitions from the ground state to the low-excited and Rydberg states, in particular, $6 s^{2}-6 s n p(n=7-50)$ transitions, of the barium atom. The comparison of the calculated oscillator strengths with available theoretical and experimental (compillated) data is performed. The important point is linked 
with non-accounting for the polarization effect contribution into the oscillator strength value that has led to $\sim 30 \%$ difference between the empirical (compillated) and theoretical data

\section{The theoretical method}

In the relativistic energy approach [4-9], which has received a great applications during solving numerous problems of atomic, molecular and nuclear physics (e.g. , see Refs. [10-59]), the imaginary part of electron energy shift of an atom is directly connected with the radiation decay possibility (transition probability). An approach, using the Gell-Mann and Low formula with the QED scattering matrix, is used in treating the relativistic atom. The total energy shift of the state is usually presented in the form:

$$
\Delta \mathrm{E}=\operatorname{Re} \Delta \mathrm{E}+\mathrm{i} \Gamma / 2
$$

where $\mathrm{G}$ is interpreted as the level width, and the decay possibility $\mathrm{P}=\mathrm{G}$. The imaginary part of electron energy of the system, which is defined in the lowest order of perturbation theory as [4]:

$$
\operatorname{Im} \Delta E(B)=-\frac{e^{2}}{4 \pi} \sum_{\substack{\alpha>n>f \\[\alpha<n \leq f]}} V_{\alpha n \alpha n}^{\left|\omega_{\alpha n}\right|}
$$

where $(a>n>f)$ for electron and $(a<n<f)$ for vacancy. The matrix element is determined as follows:

$$
\begin{aligned}
V_{i j k l}^{|\omega|}= & \iint d r_{1} d r_{2} \Psi_{i}^{*}\left(r_{1}\right) \Psi_{j}^{*}\left(r_{2}\right) \frac{\sin |\omega| r_{12}}{r_{12}}(1- \\
& \left.-\alpha_{1} \alpha_{2}\right) \Psi_{k}^{*}\left(r_{2}\right) \Psi_{l}^{*}\left(r_{1}\right)
\end{aligned}
$$

The separated terms of the sum in (3) represent the contributions of different channels and a probability of the dipole transition is:

$$
\Gamma_{\alpha_{n}}=\frac{1}{4 \pi} \cdot V_{\alpha_{n} \alpha_{n}}^{\left|\omega_{\alpha_{n}}\right|}
$$

The corresponding oscillator strength:

$$
g f=\lambda_{g}^{2} \cdot \Gamma_{\alpha_{n}} / 6.67 \cdot 10^{15}
$$

where $g$ is the degeneracy degree, 1 is a wavelength in angstrems $(\AA)$. Under calculating the matrix elements (3) one should use the angle symmetry of the task and write the expansion for potential $\sin |\mathrm{w}| \mathrm{r} 12 / \mathrm{r} 12$ on spherical functions as follows [4]:

$$
\begin{gathered}
\frac{\sin |\omega| r_{12}}{r_{12}}=\frac{\pi}{2 \sqrt{r_{1} r_{2}}} \sum_{\lambda=0}^{\infty}(\lambda) J_{\lambda+1 / 2}\left(|\omega| r_{1}\right) . \\
. J_{\lambda+1 / 2}\left(|\omega| r_{1}\right) J_{\lambda+1 / 2}\left(|\omega| r_{2}\right) P_{\lambda}\left(\cos r_{1} r_{2}\right)
\end{gathered}
$$

where $J$ is the Bessel function of first kind and $(1)=21+1$. This expansion is corresponding to usual multipole one for probability of radiative decay. Substitution of the expansion (5) to matrix element of interaction gives as follows [5-8]:

$$
\begin{gathered}
V_{1234}^{\omega}=\left[\left(j_{1}\right)\left(j_{2}\right)\left(j_{3}\right)\left(j_{4}\right)\right]^{1 / 2} \sum_{\lambda \mu}(-1)^{\mu}\left(\begin{array}{cc}
j_{1} j_{3} & \lambda \\
m_{1}-m_{3} & \mu
\end{array}\right) \times \\
\times \operatorname{Im} Q_{\lambda}(1234) \\
Q_{\lambda}=Q_{\lambda}^{\mathrm{Cul}}+Q_{\lambda}^{\mathrm{B}}
\end{gathered}
$$

where $j_{i}$ is the total single electron momentums, $m_{i}$ - the projections; $Q^{\text {Cul }}$ is the Coulomb part of interaction, $Q^{B r}$ - the Breit part. Their detailed definitions are presented in Refs. [4,20]. The detailed expressions for the Coulomb and Breit parts and the corresponding radial $R_{l}$ and angular $S_{l}$ integrals can be found in Refs. [22-32].The total probability of a $\lambda$ - pole transition is usually represented as a sum of the electric $P_{\lambda}^{E}$ and magnetic $P_{\lambda}^{M}$ parts. The electric (or magnetic) $\lambda$ - pole transition $\gamma \rightarrow \delta$ connects two states with parities which by $\lambda($ or $\lambda+1)$ units. In our designations

$$
\begin{gathered}
P_{i}^{E}(\gamma \rightarrow \delta)=2(2 j+1) Q_{i}^{E}(\gamma \delta ; \gamma \delta) \\
P_{i}^{M}(\gamma \rightarrow \delta)=2(2 j+1) Q_{i}^{M}(\gamma \delta ; \gamma \delta) \\
Q_{i}^{E}=Q_{i}^{C \nu}+Q_{i, \lambda-1}^{B \gamma}+Q_{i, \lambda+1}^{E \gamma} \\
Q_{i}^{M}=Q_{i, \lambda}^{B \gamma} .
\end{gathered}
$$

In our work the relativistic wave functions are determined by solution of the Dirac equation with the potential, which includes the modified Kohn-Sham exchange potential [17] insist of the standard Fock one. The important point of 

spectroscopic parameters of the barium spectra we are limited by non-accounting for the polarization effect contribution and other correlation corrections. Its consistent and accurate accounting will be considered in the next paper. All calculations are performed on the basis of the modified numeral code Superatom (version 93).

\section{Results and conclusion}

Table 1, 2 shows the energies and oscillators strengths of the transitions between the terms of the configurations $6 s^{2}-6 s n p(n \sim 50)$. Taking into account a great size of the obtained data we are limited below only by some data. As it has been underlined above, here during this preliminary studying the energy and spectroscopic parameters of the barium spectra we were limited by nonaccounting for the polarization effect contribution and other correlation corrections. By the way, it is well-known that the similar complicated atomic systems, spectra and corresponding computing the radiative parameters require very accurate accounting for the different groups of the manybody exchange-correlation effects (see, for example, refs. [5-25]). Moreover, only such a way is able to provide spectral data with sufficient accuracy for modern spectroscopic applications. Such calculations are now in progress and more full information will be presented in the next papers special Preprint.

Table 1

The energy $\left(\mathrm{cm}^{-1}\right)$ and the oscillators strengths of $6 s^{2}-6 s n p$ transitions (see text)

\begin{tabular}{|c|c|c|c|c|}
\hline Transition & Terms & $\begin{array}{c}\text { E }\left(\mathrm{cm}^{-1}\right) \\
{[2]}\end{array}$ & $\begin{array}{c}\text { gf } \\
{[2]}\end{array}$ & gf (our) \\
\hline $6 s^{2}-6 s 13 p$ & ${ }^{1} S-{ }^{1} P^{\circ}$ & 40763 & $2.1-4$ & $1.3-4$ \\
\hline $6 s^{2}-6 s 15 p$ & ${ }^{1} S-{ }^{1} P^{\circ}$ & 41183 & $1.4-3$ & $0.8-3$ \\
\hline $6 s^{2}-6 s 16 p$ & ${ }^{1} S-{ }^{1} P^{o}$ & 41306 & $6.0-4$ & $3.8-4$ \\
\hline
\end{tabular}

The energy $\left(\mathrm{cm}^{-1}\right)$ and the oscillators strengths of the $6 s^{2}-6 s n p$ transitions $(n=16-30$; our data)

\begin{tabular}{|c|c|c|c|}
\hline Transition & Terms & E $\left(\mathrm{cm}^{-1}\right)$ & gf \\
\hline $6 s^{2}-6 s 16 p$ & ${ }^{1} S-{ }^{1} P^{\circ}$ & 41306 & $3.7-4$ \\
\hline $6 s^{2}-6 s 20 p$ & ${ }^{1} S-{ }^{1} P^{\circ}$ & 41615 & $0.6-4$ \\
\hline $6 s^{2}-6 s 21 p$ & ${ }^{1} S-{ }^{1} P^{o}$ & 41662 & $1.8-5$ \\
\hline $6 s^{2}-6 s 30 p$ & ${ }^{1} S-{ }^{1} P^{\circ}$ & 41871 & $2.2-5$ \\
\hline
\end{tabular}

We are planning to pay especial attention on the accurate accounting for the different groups of the many-body exchange-correlation effects and consider a problem of using the optimized one-particle representation and account for the polarization effect. It is obvious that a possible estimate of the gauge-non-invariant contributions (the difference between the oscillator strengths values calculated with using the transition operator in the form of length and velocity) will be of order $40 \%$, i.e. results, obtained with using different photon propagator gauges (Coulomb, Landau etc) differ significantly (see [6, 60-62]).

\section{References}

1. Luc Koenig E., Aymar M., Van Leeuwen R., Ubachs W., Hogervorst W., The $5 \mathrm{~d} 5 \mathrm{~g}$ states in $\mathrm{Ba} / /$ Phys.Rev.A-1995.Vol.52.-P.208-215

2. Klose J., Fuhr J., Wiese W., Critically evaluated atomic transition probabilities for BaI, BaII///J. Phys. Ch. Ref. Dat.-2002.-Vol. 31.-P.217-230.

3. Ivanova E.P., Grant I., Oscillator strength anomalies in $\mathrm{Ne}$ isoelectronic sequence with applications to X-ray laser modeling// J. Phys. B:At.Mol.Phys.1998-Vol.31.-P.2871.

4. Ivanov L.N.,Ivanova E.P., Extrapolation of atomic ion energies by model potential method: Na-like spectra// Atom. Data Nucl Data Tab.-1999.-Vol.24.P.95-121.

5. Ivanov L.N., Ivanova E.P., Knight L., Energy Approach to consistent QED theory for calculation of electron-col- 
lision strengths/ //Phys.Rev.A.-1993.Vol.48.-P.4365-4374.

6. Glushkov A.V.,Ivanov L.N., Radiation Decay of Atomic States: atomic residue polarization and gauge noninvariant contributions//Phys. Lett.A.1997-Vol.170(1).-P.33-36.

7. Glushkov A.V.,Ivanov L.N., DC Strong-Field Stark-Effect: consistent quantum-mechanical approach $/ / \mathrm{J}$. Phys.B: At. Mol. Opt. Phys.-1993.Vol.26.-P.L379-386.

8. Glushkov A.V., Relativistic Quantum Theory. Quantum, mechanics of Atomic Systems.-Odessa: Astroprint, 2008.-700P.

9. Glushkov A.V., Khetselius O.Y., Malinovskaya S.V., New laser-electron nuclear effects in the nuclear $\gamma$ transition spectra in atomic and molecular systems// Frontiers in Quantum Systems in Chemistry and Physics. Series: Progress in Theoretical Chemistry and Physics Eds. S.Wilson, P.J.Grout, J. Maruani, G. Delgado-Barrio, P. Piecuch (Springer).-2008.-Vol.18.-525-541.

10. Glushkov A.V., Khetselius O.Yu., Svinarenko A.A., Prepelitsa G.P., Energy approach to atoms in a laser field and quantum dynamics with laser pulses of different shape//In: Coherence and Ultrashort Pulse Laser Emission, Ed. by Dr. F. Duarte (InTech).-2010.P.159-186.

11. Glushkov A.V., Khetselius O., Svinarenko A, Relativistic theory of cooperative muon-g gamma-nuclear processes: Negative muon capture and metastable nucleus discharge// Advances in the Theory of Quantum Systems in Chemistry and Physics. Ser.: Progress in Theor. Chem. and Phys., Eds. P.Hoggan, E.Brandas, J.Maruani, G. DelgadoBarrio, P.Piecuch (Springer).-2012.Vol.22.-P.51.

12. Glushkov A.V., Svinarenko A.A., Nuclear quantum optics: Energy approach to multi-photon resonances in nuclei // Sensor Electr. and Microsyst. Techn.-2010.-N2.-P.5-10.
13. Glushkov A.V., Energy approach to resonance states of compound super-heavy nucleus and EPPP in heavy nuclei collisions// Low Energy Antiproton Phys. AIP Conference Proceedings.-2005.Vol. 796.-P.206-210.

14. Malinovskaya S.V., Glushkov A.V., Khetselius O.Yu., Lopatkin Yu., Loboda A.V., Svinarenko A., Nikola L., Perelygina T., Generalized energy approach to calculating electron collision crosssections for multicharged ions in a plasma: Debye shielding model// Int. Journ. Quant. $\quad$ Chem.-2011.-Vol.111,N2.P.288-296.

15. Malinovskaya S., Glushkov A.V., Khetselius O.Yu., Svinarenko A.A., Mischenko E., Florko T., Optimized perturbation theory scheme for calculating the interatomic potentials and hyperfine lines shift for heavy atoms in the buffer inert gas//Int. J. Quant.Chem.-2009.Vol.109.-P. 3325-3329.

16. Glushkov A., Malinovskaya S., Prepelitsa G., Ignatenko V., Manifestation of the new laser-electron nuclear spectral effects in thermalized plasma: QED theory of cooperative laser-electron- nuclear processes //J.Phys.: Conf. Ser.-2005.-Vol.11.-P.199.

17. Glushkov A.V., Khetselius O.Yu., Lovett L., Electron-b-Nuclear Spectroscopy of Atoms and Molecules and Chemical Bond Effect on the b-Decay parameters// Advances in the Theory of Atomic and Molecular Systems Dynamics, Spectroscopy, Clusters, and Nanostructures. Series: Progress in Theor. Chem. and Phys., Eds. Piecuch P., Maruani J., Delgado-Barrio G., Wilson S. (Springer).-2009.-Vol.20.-P.125-152.

18. Glushkov A.V., Malinovskaya S.V., Ambrosov S., Shpinareva I.M., Troitskaya O.V., Resonances in quantum systems in strong external fields consistent quantum approach// J. of Techn.Phys.1997.-Vol.38, Iss.2.-P.215-218.

19. Glushkov A., Malinovskaya S., Loboda A., Shpinareva I.,Gurnitskaya E., Korchevsky D., Diagnostics of the colli- 
sionally pumped plasma and search of the optimal plasma parameters of x-ray lasing: Calculation of electron-collision strengths and rate coefficients for $\mathrm{Ne}$ like plasma// J. Phys.: Conf.Ser.-2005.Vol.11.-P.188-198.

20. Glushkov A.V., Khetselius O.Yu., Loboda A., Ignatenko A., Svinarenko A., Korchevsky D., Lovett L., QED approach to modeling spectra of the multicharged ions in a plasma: Oscillator and electronion collision strengths//Spectral Line Shapes. AIP Conf.Proc.-2008.Vol.1058.-P.175-177

21. Malinovskaya S.V., Dubrovskaya Yu.V., Vitavetskaya L.A., Advanced quantum mechanical calculation of the beta decay probabilities// Low Energy Antiproton Phys. AIP Conference Proceedings.2005.-Vol. 796.-P.201-205.

22. Glushkov A.V., Ambrosov S.V., Loboda A., Gurnitskaya E.P., Prepelitsa G.P., Consistent QED approach to calculation of electron-collision excitation cross-sections and strengths: Ne-like ions//Int. Journ. Quant. Chem.-2005.Vol.104, N4 .-P. 562-569.

23. Glushkov A.V., Ambrosov S., Ignatenko A., Korchevsky D., DC Strong Field Stark effect for non-hydrogenic atoms: Consistent quantum mechanical approach// Int.Journ. Quant. Chem.-2004.Vol.99,N6.-P.936-939.

24. Glushkov A.V, Malinovskaya S.V, Chernyakova Y.G., Svinarenko A.A., Cooperative laser-electron-nuclear processes: QED calculation of electron satellites spectra for multi-charged ion in laser field// Int. J. Quant. Chem.-2004.Vol.99.-P.889-893.

25. Glushkov A.V, Khetselius O.Yu, Malinovskaya S.V, Optics and spectroscopy of cooperative laser-electron nuclear processes in atomic and molecular systems - new trend in quantum optics// Europ. Phys. Journ. ST.-2008.Vol.160,N1.-P.195-204.

26. Malinovskaya S., Glushkov A., Dubrovskaya Yu., Vitavetskaya L., Quantum calculation of cooperative muon- nuclear processes: discharge of metastable nuclei during negative muon capture// Recent Advances in Theory of Chemical and Physical Systems (Springer).-2006.-Vol.15.-P.301-307.

27. Glushkov A.V., Khetselius O.Yu., Loboda A., Svinarenko A., QED approach to atoms in a laser field: Multi-photon resonances and above threshold ionization// Frontiers in Quantum Systems in Chemistry and Physics, Ser.: Progress in Theor.Chem.and Phys.; Eds. S.Wilson, P.Grout, J. Maruani et al, (Springer), 2008.-Vol.18.-P.543-560.

28. Glushkov A.V., Dan'kov S., Prepelitsa G., Polischuk V., Efimov A., Qed theory of nonlinear interaction of the complex atomic systems with laser field multiphoton resonances// Journal of Tech. Phys.-1997.-Vol.38.-P.219-222

29. Glushkov A.V., Ambrosov S.V., Loboda A.V., Gurnitskaya E.P., Khetselius O.Yu., QED calculation of heavy multicharged ions with account for the correlation, radiative and nuclear effects// Recent Advances in Theor. Phys. and Chem. Systems.-2006.-Vol.15.P.285-299.

30. Glushkov A.V., Calculation of parameters of the interaction potential between excited alkali atoms and mercury atoms-the Cs-, Fr-Hg interaction// Optika i Spektr.-1994.-Vol.77 (1).-P.5-10.

31. Glushkov A.V.,Khetselius O.Yu., Gurnitskaya E.P., Korchevsky D.A., Loboda A.V., Prepelitsa G.P., Sensing the electron-collision excitation cross-sections for Ne-like ions of Fe in a plasma in the Debye shileding approximation//Sensor Electr. and Microsyst. Techn.-2007.N2.-P.9-13

32. Svinarenko A.A., Ignatenko A.V., Ternovsky V.B., Nikola V.V., Seredenko S.S., Tkach T.B., Advanced relativistic model potential approach to calculation of radiation transition parameters in spectra of multicharged ions// J.Phys.:Conf. Ser.-2014.-Vol.548.P. 012047

33. Svinarenko A.A., Khetselius O.Yu., 
Buyadzhi V.V., Florko T.A., Zaichko P.A., Ponomarenko E.L., Spectroscopy of Rydberg atoms in a Black-body radiation field: Relativistic theory of excitation and ionization// J. Phys.: Conf. Ser.-2014.-Vol. 548.-P. 012048.

34. Glushkov A., Khetselius O., Bunuakova Y., Buyadzhi V., Brusentseva S., Zaichko P., Sensing interaction dynamics of chaotic systems within chaos theory and micro-system technology Geomath with application to neurophysiological systems// Sensor Electr. Microsyst.Techn.-2014-Vol. 11.-P.62

35. Prepelitsa G.P., Glushkov A.V., Lepikh Ya.I., Buyadzhi V.V., Ternovsky V.B., Zaichko P.A., Chaotic dynamics of nonlinear processes in atomic and molecular systems in electromagnetic field and semiconductor and fiber laser devices: new approaches, uniformity and charm of chaos// Sensor Electr. and Microsyst. Techn.-2014.-Vol.11,N4.-P.43-57.

36. Glushkov A.V., Relativistic and correlation effects in spectra of atomic systems.-Odessa: Astroprint.-2006.$400 \mathrm{P}$.

37. Glushkov A.V., Atom in electromagnetic field.-Kiev: KNT, 2005.-450P.

38. Khetselius O.Yu., Hyperfine structure of atomic spectra.-Odessa: Astroprint, 2008.

39. Khetselius O.Yu., Hyperfine structure of radium//Photoelectronics.-2005-N14P.83-85

40. Khetselius O., Spectroscopy of cooperative electron-gamma-nuclear processes in heavy atoms: NEET effect// J. Phys.: Conf. Ser.-2012.- Vol.397.-P.012012

41. Glushkov A., Malinovskaya S., Gurnitskaya E., Khetselius O.Yu.,Dubrovskaya Yu., Consistent quantum theory of the recoil induced excitation and ionization in atoms during capture of neutron// Journal of Physics: Conf. Series (IOP).2006.- Vol.35.-P.425-430.

42. Khetselius O.Yu., Quantum Geometry: New approach to quantization of the quasistationary states of Dirac equation for super heavy ion and calculating hy- perfine structure parameters// Proc. Int. Geometry Center.-2012.-Vol.5,№ 3-4.P.39-45.

43. Glushkov A., Khetselius O., Svinarenko A., Theoretical spectroscopy of autoionization resonances in spectra of lanthanide atoms// Physica Scripta.2013.-Vol.T153.-P.014029.

44. Glushkov A., Khetselius O., Gurnitskaya E., Loboda A.,Sukharev D., Relativistic quantum chemistry of heavy ions and hadronic atomic systems: spectra and energy shifts//Theory and Applications of Computational Chemistry. AIP Conf.Proceedings.-2009.-Vol.1102.P.168-171.

45. Khetselius O.Yu., Relativistic calculating the spectral lines hyperfine structure parameters for heavy ions//Spectral Line Shapes, AIP Conf. Proc.-2008.Vol.1058.-P.363-365.

46. Khetselius O., Glushkov A., Gurnitskaya E., Loboda A., Mischenko E., Florko T., Sukharev D., Collisional Shift of the Tl hyperfine lines in atmosphere of inert gases// Spectral Line Shapes, AIP Conf. Proc.-2008.-Vol.1058.-P.231-233.

47. Khetselius O.Yu., Hyperfine structure of energy levels for isotopes ${ }^{73} \mathrm{Ge},{ }^{75} \mathrm{As}$, ${ }^{201} \mathrm{Hg} / / \quad$ Photoelectronics.-2007.-N16.P.129-132.

48. Khetselius O.Y., Gurnitskaya E.P., Sensing electric and magnetic moments of a nucleus in the N-like ion of $\mathrm{Bi} / /$ Sensor Electr. and Microsyst. Techn.-2006.N3.-P.35-39.

49. Khetselius O.Y., Gurnitskaya E.P., Sensing the hyperfine structure and nuclear quadrupole moment for Ra//Sensor Electr. and Microsyst. Techn.-2006.N2.-P.25-29.

50. Florko T.A., Loboda A.V., Svinarenko A.A., Sensing forbidden transitions in spectra of some heavy atoms and multicharged ions: New theoretical scheme// Sensor Electr. and Microsyst. Techn.-2009.-N3.-P.10-15.

51. Khetselius O.Yu., Florko T.A., Svinarenko A.A., Tkach T.B., Radiative and collisional spectroscopy of hyperfine 
lines of the Li-like heavy ions and $\mathrm{Tl}$ atom in atmosphere of inert gas//Phys. Scripta.-2013.-Vol.T153-P. 014037.

52. Khetselius O.Yu., Turin A.V., Sukharev D.E., Florko T.A., Estimating of Xray spectra for kaonic atoms as tool for sensing the nuclear structure// Sensor Electr. and Microsyst. Techn.-2009.N1.-P.30-35.

53. Khetselius O.,On possibility of sensing nuclei of rare isotopes by means of laser spectroscopy of hyperfine structure// Sensor Electr. Microsyst.Techn.-2008.Vol.3.-P.28.

54. Svinarenko A.A., Glushkov A.V., Loboda A.V., Sukharev D.E., Dubrovskaya Yu.V., Mudraya N.V., Serga I.N., Green's function of the Dirac equation with complex energy and non-singular central nuclear potential//Quantum Theory: Reconsideration of Foundations. AIP Conf. Proceedings.-2010.Vol.1232.-P.259-266.

55. Buyadzhi V., Chernyakova Yu., Smirnov A., Tkach T., Electron-collisional spectroscopy of atoms and ions in plasma: Be-like ions// Photoelectronics.-2016.Vol.25.-P.97-101.

56. Sukharev D.E., Khetselius O.Yu., Dubrovskaya Yu.V., Sensing strong interaction effects in spectroscopy of hadronic atoms// Sensor Electr. and Microsyst. Techn.-2009.-N3.-P.16-21.

57. Glushkov A.V., Khetselius O.Yu., Kuzakon V., Prepelitsa G.P., Solyanikova E.P., Svinarenko A., Modeling of interaction of the non-linear vibrational systems on the basis of temporal series analyses (application to semiconductor quantum generators)// Dynamical Systems- Theory and Applications.-2011.BIF110.
58. Glushkov A., Khetselius O.Y., Brusentseva S., Zaichko P., Ternovsky V., Studying interaction dynamics of chaotic systems within a non-linear prediction method: application to neurophysiology// Advances in Neural Networks, Fuzzy Systems and Artificial Intelligence, Ser: Recent Adv. in Computer Engineering, Ed. J.Balicki.-2014.Vol.21.-P.69-75.

59. Glushkov A.V., Operator Perturbation Theory for Atomic Systems in a Strong DC Electric Field//Advances in Quantum Methods and Applications in Chemistry, Physics, and Biology. Series: Frontiers in Theoretical Physics and Chemistry, Eds. M.Hotokka, J.Maruani, E. Brändas, G.DelgadoBarrio (Springer).-2013.-Vol. 27.P.161-177.

60. Glushkov A., Khetselius O., Prepelitsa G., Svinarenko A., Geometry of Chaos: Theoretical basis's of a consistent combined approach to treating chaotic dynamical systems and their parameters determination //Proc. Int. Geometry Center".-2013.-Vol.6, N1.-P.43-48.

61. Svinarenko A., Nikola L., Prepelitsa G., Tkach T., Mischenko E., Auger (autoioni-zation) decay of excited states in spectra of multicharged ions: Relativistic theory//AIP Conf. Proc.-2010.Vol.1290, N1 P.94-98.

62. Florko T.A., Ignatenko A.V., Svinarenko A.A., Tkach T.B., Ternovsky V.B, Advanced relativistic model potential approach to calculation of the radiation transition and ionization characteristics for Rydberg atoms// Photoelectronics.-2014.-Vol.23.P.91-95.

This article has been received in May 2017 


\title{
RELATIVISTIC CALCULATION OF OSCILLATOR STRENGTHS OF THE RADIATION TRANSITIONS BETWEEN BARIUM RYDBERG STATES
}

\begin{abstract}
Summary
The combined relativistic energy approach and relativistic many-body perturbation theory with the zeroth order Dirac-Kohn-Sham one-particle approximation are used for preliminary estimating the energies and oscillator strengths of radiative transitions from the ground state to the low-excited and Rydberg states, in particular, $6 \mathrm{~s}^{2}-6 \mathrm{snp}(\mathrm{n}=7-50)$ transitions, of the barium atom. The comparison of the calculated oscillator strengths with available theoretical and experimental (compillated) data is performed. The important point is linked with non-accounting for the polarization effect contribution into the oscillator strength value that has led to $\sim 40 \%$ difference between the empirical (compillated) and theoretical data.
\end{abstract}

Key words: relativistic theory, oscillator strengths, radiative transitions

УДК 539.182

Е. В. Терновский, О. А. Антошкина, Т. А. Флорко, Т. Б. Ткач

\section{РЕЛЯТИВИСТСКИЙ РАСЧЕТ СИЛ ОСЦИЛЛЯТОРОВ РАДИАЦИОННЫХ ПЕРЕХОДОВ МЕЖДУ РИДБЕРГОВСКИМИ СОСТОЯНИЯМИ БАРИЯ}

\begin{abstract}
Резюме
Комбинированный релятивистский энергитический подход и релятивистская теория возмущений многих тел с дирак-кон-шэмовским одночастичным приближением нулевого порядка используются для предварительной оценки энергий и сил осцилляторов радиационных переходов из основного состояния в низкие возбужденные и ридберговские состояния, в частности, 6s ${ }^{2}-6 \mathrm{snp}(\mathrm{n}=7-50)$ переходоваирма бария. Выполнено сравнение расчетных сил осцилляторов с имеющимися теоретическими и экспериментальными данными. Важнейшая особенность связана с неучетом вклада в величину силы осцилятора, обусловленного эффектом поляризации остова и некоторіми другими корреляционными поправками, что приводит к $40 \%$ отличию между экспериментальными (компиллированными) и теоретическими данными.
\end{abstract}

Ключевые слова: релятивистская теория, силы осцилляторов, радиационные переходы. 


\section{РЕЛЯТИВІСТСЬКИЙ РОЗРАХУНОК СИЛ ОСЦИЛЯТОРІВ РАДІАЦІЙНИХ ПЕРЕХОДІВ МІЖ РІДБЕРГІВСЫКИМИ СТАНАМИ БАРІЯ}

\section{Резюме}

Комбінований релятивістський енергетичний підхід і релятивістська багаточастинкова теорія збурень 3 дірак-кон-шемівським одночастинковим наближенням нульового порядку використовуються для попередньої оцінки енергій і сил осциляторів радіаційних переходів 3 основного стану в низько збуджені і рідбергівські стани, зокрема, 6s2 -6snp (n = 7 -50) переходів атома барія. Виконано порівняння розрахункових сил осциляторів 3 наявними теоретичними і експериментальними даними. Найважливіша особливість даного розрахунку пов'язана 3 неврахуванням вкладу в величину сили осцилятора, обумовленого ефектом поляризації остова та декотрими іншими кореляційними поправками, що призводить до $\sim 40 \%$ відмінності між експериментальними (компіллірованними) і теоретичними даними.

Ключові слова: релятивістська теорія, сили осцилляторів, радіаційнні переходи, рідбергівські стани. 